\title{
Idoso no Brasil: agressões, políticas e programas públicos - revisão de literatura
}

\author{
Cassiana Regina Leindecker \\ Rose Mari Bennemann \\ Regiane da Silva Macuch
}

\begin{abstract}
Resumo: Estudo sobre violência contra o idoso. Método: revisão sistemática de literatura nas bases de dados PubMed e Scielo a partir de artigos completos publicados entre os anos 2014 e 2018, em língua portuguesa e inglesa. Os descritores utilizados para pesquisa foram "violência", "idoso" e "maus-tratos"no título e/ou resumo. Resultados: Dos 138 artigos encontrados, 17 atenderam aos critérios de inclusão. Após a leitura na integra, evidenciou-se que o principal agressor é um membro da família do idoso e que os tipos de violências são variados, dificultando a identificação dos casos. Também ficou evidenciado que o aliado fundamental na identificação e combate à violência é o profissional da saúde. Conclusões. Envelhecer com qualidade de vida tem sido um desafio para os indivíduos e sociedade ainda em função dos altos índices de violências contra o idoso.
\end{abstract}

Palavras-chave: Políticas públicas, violência, idoso.

\section{Elderly in Brazil: aggressions, policies and public programs - literature review}

\begin{abstract}
This study consists of a literature review on the topic of abuse against elderly people. Research articles in English and Portuguese, published between 2014 and 2018, were collected via the academic search engines PubMed and Scielo on the basis of the tags 'violence', 'elderly', and 'mistreatment', which were to be found in the title and/or abstract. From the 138 articles initially found, 17 met further screening criteria and were selected for analysis. Our analysis shows that the main aggressor in cases of abuse against elderly people is a close family member and that the most frequent types of abuse are varied in nature, which translates in difficulties in detecting abuse cases in the first place. The results of the analysis also highlight the fact that health professionals are a key agent in the detection of abuse.
\end{abstract}

Keywords: Public policies, violence, elderly.

\section{Introdução}

Envelhecer não é doença e deveria ocorrer com qualidade de vida. Caracterizado como processo dinâmico e progressivo marcado por mudanças fisiológicas, afetivas, cognitivas e sociais que deixam o indivíduo suscetível às agressões intrínsecas e extrínsecas que podem propiciar adoecimento (Assis \& Parra, 2014).

Apopulação mundial desses sujeitosidosos entre os anos 2000-2050 subirá de 600 milhões para 2 bilhões.Com este aumento, diversas mudanças e preocupações sociais, econômicas e políticas também aumentarão, os maiores aumentos aconteceram na Ásia Oriental e Pacífico de 7,4\% em 2010, para 22,2\% (Programa das Nações Unidas para o Desenvolvimento [PNUD], 2014).

Em 2015 haviam 810 milhões de idosos no mundo e a cada segundo duas pessoas completam 60 anos, isso pode ser considerado uma revolução da longevidade. Estima- 
se que no ano de 2050 uma grande parte dos países desenvolvidos estarão com $30 \%$ da população com 60 anos, com exceção do Japão que já atingiu esse percentual em 2015 (Centro internacional de longevidade Brasil [ILC-BRASIL], 2015).

Esse crescimento a nível mundial é explicado em função das taxas de fecundidade terem diminuído e a expectativa de vida ter aumentado. No Brasil 75,2 anos era a expectativa de vida no ano de 2014, ou seja, um aumento de 29,7 anos para ambos os sexos mostrando esse aumento considerável quando comparado aos indicadores observados em 1940 (28,7 anos para homens e 30,5 anos para mulheres). (Instituto Brasileiro de Geografia e Estatística [IBGE], 2017a).

O prolongamento da expectativa de vida da população mundial também está relacionado aos avanços tecnológicos, médicos e descobertas de novos métodos diagnósticos e terapêuticos. Para além das medidas preventivas e de melhores condições de vida, pode também estar relacionado com o envelhecimento (Silva, 2016). Em outras palavras, "quando a mortalidade inicial é alta, seu declínio torna a população mais jovem e, quando a mortalidade é baixa, declínios adicionais tornam a população mais velha" (Mesquita, 2014).

Com relação às taxas de fecundidade, elas estão despencando a cada ano, em 2010, 75 países inclusive, alguns de baixa renda, tinham taxas abaixo de nível de reposição, ou seja, morrendo mais pessoas que nascendo, colocando em questão também os padrões familiares e sociais de sustento e cuidado ao idoso. (ILC/BRASIL, 2015). De acordo com, em projeção atualizada para 2030, o público idoso no Brasil somará 13,44\% da população total, o que é um percentual significativo. (IBGE, 2017b).

Acompanhar o progressivo aumento dos idosos no Brasil e ainda suprir as necessidades sociais que esse aumento está trazendo é um desafio para as políticas públicas, programas e serviços que acolhem essas particularidades (Silva, 2016).

\section{Políticas e programas públicos voltados ao idoso no Brasil}

Envelhecer de forma saudável em todos os aspectos é uma questão de direitos humanos. Neste sentido, foi promulgada em Janeiro de 1994 a Lei no 8.842 que dispõe sobre a Política Nacional do Idoso (PNI). A partir dela foi criado o Conselho Nacional do Idoso entre outras providências como, por exemplo, o esboço do plano de ação para o enfrentamento da violência contra a pessoa idosa. (Lei n. 8.842, 1994).

A PNI busca promover formas de colocar em prática os direitos de envelhecer com segurança por meio de ações conjuntas entre governo e sociedade para a construção de uma rede de proteção a esse segmento populacional. A finalidade da Lei em seu artigo $1^{\circ}$ assim está descrita: “A PNI tem por objetivo assegurar os direitos sociais do idoso, criando condições para promover sua autonomia, integração e participação efetiva na sociedade" (Portaria n. 737, 2001, p. 5).

A Política Nacional de Redução da Morbimortalidade por Acidentes e Violências, aprovada pela Portaria MS/GMn ${ }^{\circ} 737$, de 16 de Maio de 2001, estabelece diretrizes gerais que visam à orientação do setor saúde para fazer frente aos agravos acidentais e violentos. Assim, “estados e municípios deverão realizar ações sistemáticas de sensibilização para a prevenção de acidentes e de violências, adequadas à cultura local” (Portaria n. 737, 2001, p. 15). 
Em $1^{\circ}$ de Outubro de 2003, a Lei ${ }^{\circ} 10.741$ cria o Estatuto do Idoso, regulamentando os direitos assegurados às pessoas com idade igual ou superior a 60 anos. Dentre estes direitos, também se estabelecem orientações e diretrizes para a atuação dos órgãos públicos e da sociedade civil para coibir as diferentes formas de violência contra a pessoa idosa, atos que causem morte, dano ou sofrimento físico ou psicológico (Lei n. 10.741, 2003).

O Estatuto do Idoso se refere às linhas de ações da política de atendimento ao idoso. Neste são destacados os serviços especiais de prevenção e atendimento às vítimas de negligência, maus-tratos, exploração, abuso, crueldade e opressão, e coloca obrigatoriedade a família, no sentido de ser responsável pelos cuidados dos membros idosos (Pinto, Barham \& Albuquerque, 2013).

A Política Nacional de Saúde da Pessoa Idosa (PNSPI), por meio da Portaria $n^{\circ} 2.528$, de 19 de Outubro de 2006, busca garantir atenção adequada e digna para a população idosa brasileira (em consonância com os princípios e as diretrizes do Sistema Único de Saúde - SUS). Ela direciona medidas individuais e coletivas em todos os níveis de atenção à saúde (Portaria n. 2.528, 2006a).

A PNPSI somou forças por meio da Portaria no 687 MS/GM, de 30 de Março de 2006, na qual, estão descritas ações específicas de prevenção da violência e estímulo à cultura de paz (Portaria n. 687, 2006b). A atenção ao idoso se enquadra nos itens da Política Nacional de Saúde da Pessoa Idosa (PNSPI):

I - Ampliação e fortalecimento da Rede Nacional de Prevenção da Violência e Promoção da Saúde; II - Investimento na sensibilização e capacitação dos gestores e profissionais de saúde na identificação e encaminhamento adequado de situações de violência intrafamiliar e sexual; IV - Implementação da ficha de notificação de violência interpessoal; $V$-Incentivo ao desenvolvimento de Planos Estaduais e Municipais de Prevenção da Violência; VI - Monitoramento e avaliação do desenvolvimento dos Planos Estaduais e Municipais de Prevenção da Violência mediante a realização de coleta, sistematização, análise e disseminação de informações; e VII - Implantação de Serviços Sentinela, que serão responsáveis pela notificação dos casos de violências. (Portaria n. 737, 2001, p. 37).

A Portaria MS/GM n ${ }^{\circ} 528$, de $1^{\circ}$ de Abril de 2013, define regras para habilitação e funcionamento dos serviços de atenção integral às pessoas em situação de violência sexual no âmbito do SUS. Em seus artigos $3^{\circ}$ e $8^{\circ}$, orienta quanto à organização do serviço de atenção integral para pessoas idosas em situação de violência sexual, mesmo por que, nos casos de violência sexual com idosos, grande parcela é desconhecida (Portaria n. 528, 2013; Lueger-Schuster, Gluck, Tran \& Zeilinger, 2012).

De acordo com o que está descrito no Estatuto do Idoso sobre a violência contra ele, considera-se que atos violentos são de notificação compulsória no âmbito da Portaria GM/MS n 1.271, de 06 de Junho de 2014. Para tal, se faz necessária a comunicação aos órgãos responsáveis, a saber, Autoridade Policial, Ministério Público, Conselho Municipal do Idoso, Conselho Estadual do Idoso e Conselho Nacional do Idoso (Portaria n. 528, 2013; Portaria n. 1.271, 2014).

Anotificação não é o único meio de se registrar ou denunciar a violência contra o idoso. No ano de 2010 o Sistema de Informação de Agravos de Notificação que é sim sistema de 
notificação e porta de entrada de denúncias, recebeu 3.593 notificações de 524 municípios, mas, São Paulo liderou com 1.073 registros feitos pela saúde (Mascarenhas et al., 2012).

Essa notificação é de fundamental importância no combate à violência contra o idoso conforme pode ser lido na Lei 12.461, de Julho de 2011 no artigo 19.Assim, “os casos de suspeita ou confirmação de violência praticada contra idosos serão objeto de notificação compulsória pelos serviços de saúde públicos e privados à autoridade sanitária, bem como serão obrigatoriamente comunicados por eles" (Lei n. 12.461, 2011, p. 1).

Existe uma palpável carência de informações no que se refere a estudos sobre a violência contra o idoso. Isso, pode levar a percepção de que a importância que se coloca para os casos de violência contra a mulher, criança e adolescente, não é semelhante à terceira idade. Os mesmos autores diante da alarmante situação da violência contra o idoso no Brasil, sugerem o investimento em instrumentos que auxiliem os serviços de saúde na identificação dos casos (Reichenheim, Paixão \& Moraes, 2008).

O Brasil, começou a tratar do assunto há pouco mais de duas décadas e isso se deve principalmente, ao protagonismo dos movimentos realizados pela própria população idosa ou por instituições aliadas, como associações de aposentados, conselhos específicos e movimentos políticos, sociais e de direitos humanos. Essas ações repercutiram no sentido da promulgação da PNI em 1994 bem como no Estatuto do Idoso em 2003. Em ambos os documentos estão declarados que os maus-tratos contra esse grupo de brasileiros constituem violações de seus direitos (Portaria n. 528, 2013).

Pensando em evitar a violência contra o idoso, verificou-se que $88 \%$ da população mundial usa como estratégia a sensibilização do promotor de saúde, ou seja, daquele profissional de saúde que está sempre em contato com a população. Outra forma implantada é informar a população sobre as violências, como identificá-las e como conseguir ajuda. Buscar melhorias nas políticas para implantações concretas também são alternativas, mas, há muita pouca pesquisa sobre a eficácia de tais programas na prevenção desse crime, sendo está, uma lacuna crítica que precisa ser preenchida (World Health Organization [WHO], 2014).

\section{Promotoria pública do idoso}

As promotorias que defendem as pessoas idosas tornaram-se necessárias da esma forma que as já existiam para a defesa de pessoas portadoras de deficiência, de pessoas acometidas por acidentes do trabalho, crianças e jovens (Mazzilli, 1994). Com a função de defender o que é peculiar ao direito de todos os cidadãos, a promotoria tem importante papel com relação aos direitos do idoso. No Estatuto do Idoso, artigo 19, o órgão deve ser comunicado por quem identificar a violência contra o idoso, sendo essa conquista um avanço importante na luta pela afirmação da dignidade da pessoa idosa (Barroso, 2016).

As Promotorias Públicas do Idoso são órgãos de administração do Ministério Público (MP), nos quais, o promotor de justiça atua de acordo com a proposta fixada pelo Procurador Geral de Justiça. Sendo assim, a partir da atuação de um promotor de justiça, o MP coloca em prática a garantia dos direitos da pessoa idosa, defendendo, amparando e protegendo os idosos quando há omissão de responsáveis (Lei Orgânica do Ministério Público do Estado do Paraná, 1999). 
Como parte dos recursos humanos do MP, os Promotores de Justiça possuem importante papel nas questões que envolvem a sociedade em prol dos direitos constitucionais e humanos do idoso (Lei Orgânica do Ministério Público do Estado do Paraná, 1999). As atribuições dos Promotores de Justiça do Idoso estão previstas no Estatuto do Idoso no que remete à violência contra o idoso.

Art. 74. Compete ao MP:

\begin{abstract}
I Instaurar o inquérito civil e a ação civil pública para a proteção dos direitos e interesses difusos ou coletivos, individuais indisponiveis e individuais homogêneos do idoso; II promover e acompanhar as ações de alimentos, de interdição total ou parcial, de designação de curador especial, em circunstâncias que justifiquem a medida e oficiar em todos os feitos em que se discutam os direitos de idosos em condições de risco; III atuar como substituto processual do idoso em situação de risco, conforme o disposto no art. 43 desta Lei; IV promover a revogação de instrumento procuratório do idoso, nas hipóteses previstas no art. 43 desta Lei, quando necessário ou o interesse público justificar; $X$ instaurar procedimento administrativo e, para instrui-lo. (Lei n. 10.741, 2003, p. 16).
\end{abstract}

O MP passa a ser parte legítima para instaurar o processo, independentemente da existência de uma representação da vítima. Desta forma, o Estatuto do Idoso considera que qualquer violência contra o idoso, qualquer ação ou omissão praticada em local público ou privado que lhe cause morte, dano ou sofrimento físico ou psicológico será tratada como crime (Boas, 2005). Assim, o objetivo deste estudo foi entender a problemática da violência contra o idoso e as políticas e programas públicos em prol desses acontecimentos de forma abrangente por meio de uma revisão de sistemática de literatura.

\title{
Metodologia
}

A revisão sistemática de literatura ocorreu a partir da busca por artigos científicos registrados nas Bases de Dados PubMed e Scielo. A coleta de dados ocorreu durante os meses de setembro e outubro de 2018. Os descritores utilizados foram "violência", "idoso" e "maus-tratos", as correspondentes em inglês, "violence", "elderly" e "mistreatment".

Como critérios de inclusão para a seleção da amostra foram considerados artigos completos que abordassem a temática em questão disponíveis dos Bases de Dados Scielo e PubMed, compreendidos no período de 2014 a 2018, nas línguas Português e Inglês que estivessem com os descritores no título e/ou resumo dos artigos. Os critérios de exclusão foram produções anteriores a 2014 e artigos que não possuíam os descritores escolhidos no título e não era dentro os idiomas selecionados, assim como artigos repetidos entre as bases de dados ou na mesma base também foram excluídos.

\section{Procedimentos}

Inicialmente, foram selecionados 160 artigos científicos de ambas as bases, que respondiam aos descritores utilizados. Após a leitura dos títulos dos artigos, notou-se que alguns deles se repetiram nas bases de dados e outros apesar de terem sido listados 
os descritores não apareciam no título subtraindo então 69 artigos. Então, foram lidos os resumos dos artigos e excluídos os que não diziam respeito ao propósito deste estudo, desse modo, foram selecionados 18 artigos (3 artigos da Base de Dados PubMed e 15 da Base de Dados Scielo) definidos para análise que preenchiam os critérios e que, posteriormente, foram lidos na íntegra.

O que as politicas e programas públicos discorrem a respeito das agressōes aos idosos no Brasil?

Buscou-se na Base de Dados Eletônicos PubMed e Scielo, de forma retrospectiva estudos que aborsassem a temática. Utilisou-se os descritores: "VIOLENCE" "VIOLÊNCIA", "ELDERLI" IDOSO e "MISTREATMENT" "MAUS-TRATOS

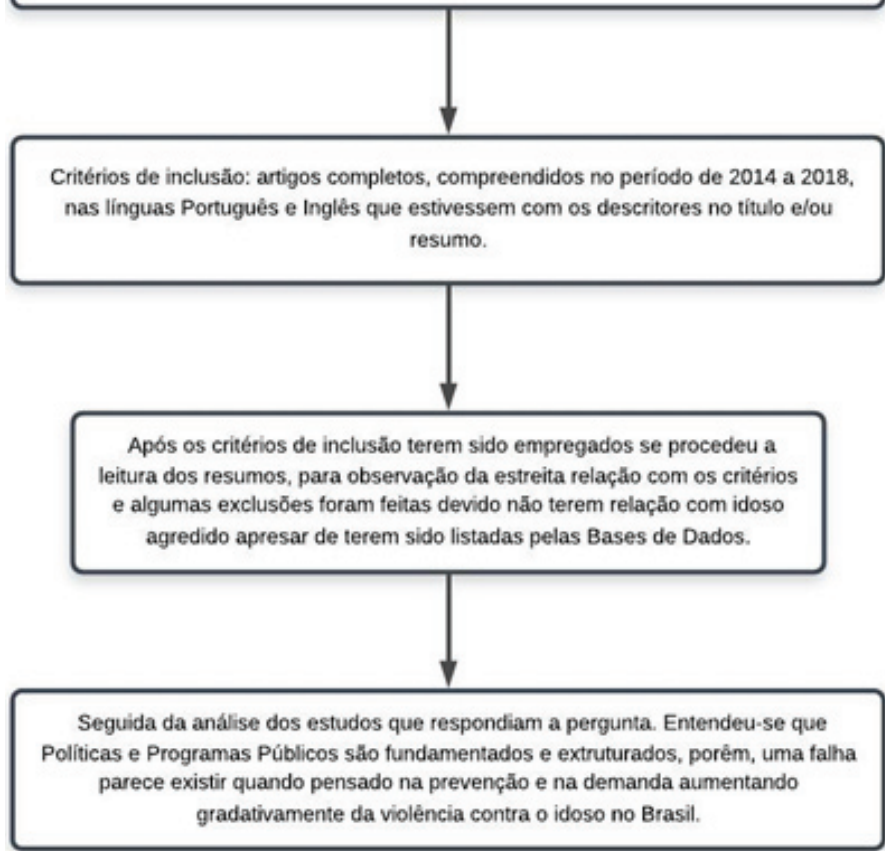

Figura 2. Processo da revisão sistemática de literatura. Com base em Sampaio e Mancini (2007) 


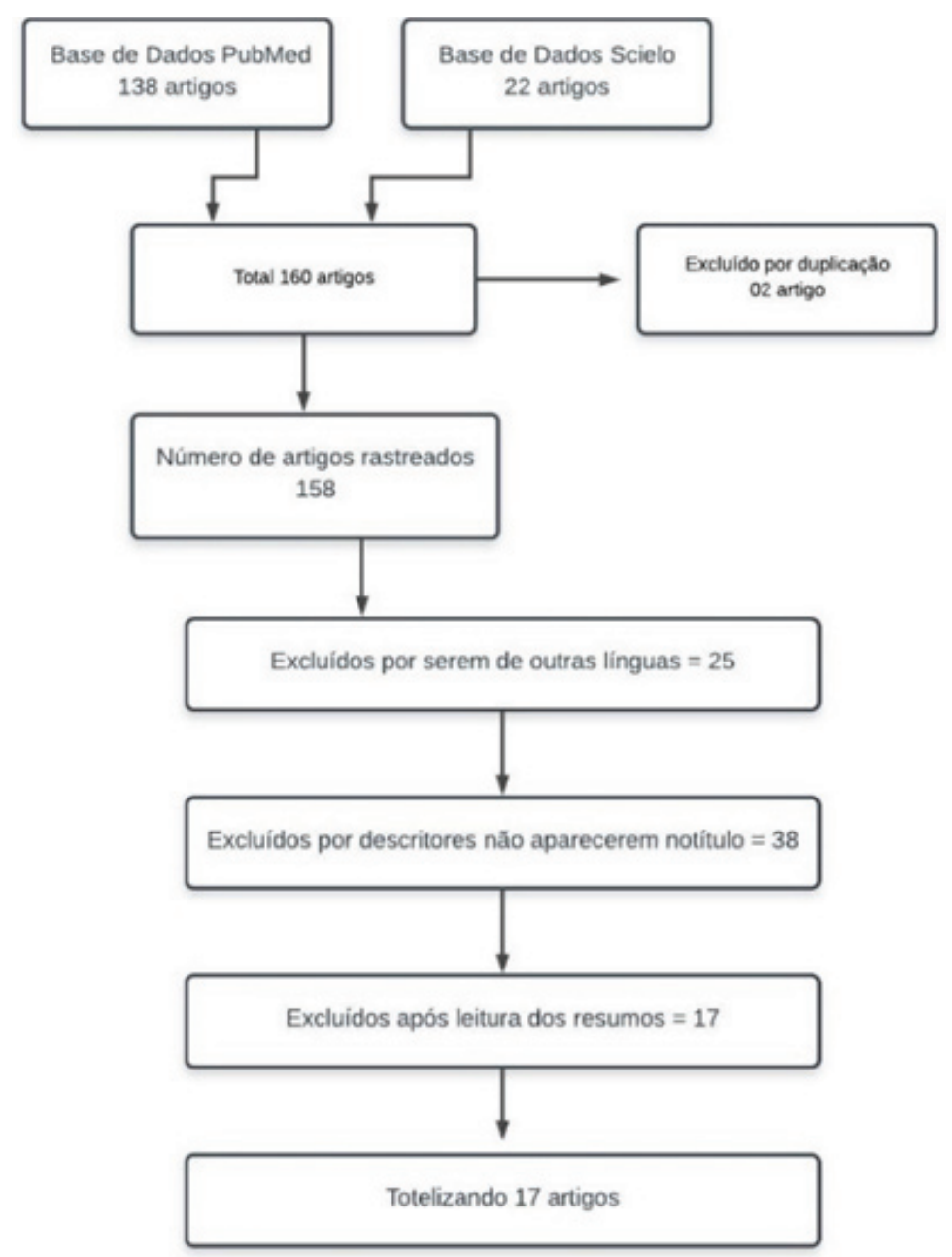

Figura 3. Resultados obtidos da revisão sistemática Com base em Sampaio e Mancini (2007)

Os artigos selecionados foram numerados conforme a língua de publicação e Base de Dados, para uma leitura aprofundada e a seguirestão apresentados na Tabela 1. 
Tabela 1

Artigos encontrados por descritores

\begin{tabular}{|c|c|c|c|c|c|c|c|c|}
\hline \multirow{3}{*}{ DESCRITORES } & \multicolumn{6}{|c|}{ BASE DE DADOS/IDIOMA } & \multirow{3}{*}{$\begin{array}{c}\text { Total de } \\
\text { artigos } \\
\text { selecionados }\end{array}$} & \multirow{3}{*}{$\begin{array}{c}\text { Total de } \\
\text { artigos } \\
\text { pós leitura } \\
\text { resumos }\end{array}$} \\
\hline & \multicolumn{3}{|c|}{ PUBMED } & \multicolumn{3}{|c|}{ SCIELO } & & \\
\hline & PT & ING & PT/ING & PT & ING & PT/ING & & \\
\hline Violência/ Violence & - & 20 & 8 & 8 & 2 & - & 37 & 10 \\
\hline Idoso/Elderly & 2 & 4 & 40 & 3 & - & - & 49 & 5 \\
\hline $\begin{array}{l}\text { Maus-tratos / } \\
\text { Mistreatment }\end{array}$ & - & - & - & 2 & - & - & 2 & 2 \\
\hline TOTAL & 2 & 25 & 48 & 6 & 9 & - & 90 & 17 \\
\hline
\end{tabular}

\section{Resultados}

Entender a problemática de forma abrangente é um primeiro passo no caminho da prevenção do abuso aos idosos, e estudar a literatura científica disponível proporciona conhecimento do fenômeno de forma mais abrangente.

Os artigos selecionados como relevantes e que atenderam aos critérios específicos do descritor "violência", "idoso" e "maus-tratos" em seus resumos, totalizaram dezoito (18) artigos que para melhor apresentação, visualização e discussão dos resultadosforamdispostos de acordo com os descritores (Tabelas 2, 3 e 4) e observa-se os artigos organizados por base de dados, ordem cronológica, título e autoria (Tabela 5).

Os artigos selecionados como relevantes e que atenderam aos critérios específicos do descritor "Violência", totalizaram dez (10) artigos (Tabela 2).

Tabela 2

Artigos selecionados com o descritor "violência".

\begin{tabular}{|c|c|c|c|c|c|}
\hline $\begin{array}{l}\text { Bases de } \\
\text { Dados }\end{array}$ & $\begin{array}{c}\text { Artigos } \\
\text { encontrados }\end{array}$ & $\begin{array}{c}\text { Artigos em } \\
\text { L. Estrangeira }\end{array}$ & $\begin{array}{l}\text { Artigos } \\
\text { excluídos }\end{array}$ & $\begin{array}{c}\text { Artigos } \\
\text { selecionados }\end{array}$ & $\begin{array}{c}\text { Artigos } \\
\text { analisados }\end{array}$ \\
\hline SCIELO & 22 & $\begin{array}{c}01 \text { (Inglês) } \\
09 \text { (Português) } \\
0 \text { (Inglês/Português) }\end{array}$ & 07 & 15 & 10 \\
\hline PUBMED & 138 & $\begin{array}{c}20 \text { (Inglês) } \\
0 \text { (Espanhol) } \\
08 \text { (Inglês/Português) }\end{array}$ & 135 & 03 & 0 \\
\hline & & & \multicolumn{2}{|c|}{ Total de Artigos Analisados } & 10 \\
\hline
\end{tabular}

Os artigos relevantes para a pesquisa sobre "Violência" demonstraram que a temática tem sido um campo de pesquisa abundante, porém, poucos estudos foram encontrados relacionando a violência com o idoso mesmo sendo de interesse social a necessidade de melhor se discutir esse fenômeno que acontece em grandes proporções com a pessoa idosa. 
Entre os artigos selecionados os nove (09) dispuseram de forma genérica a magnitude do crescimento da população idosa a nível mundial e relacionaram concepções sobre a violência contra esses indivíduos ser um problema que está acontecendo mundialmente. Somente dois (02) artigos destacam que o problema não deve ser tratado somente a nível nacional, ou seja, estar ocorrendo no mundo todo as soluções devem ser discutidas para que todos trabalhem com o mesmo propósito, não individualizando seus países.

Dentre os artigos também dois (02) destacam a importância dos profissionais de saúde no que se refere a identificação de idosos em sofrimento seja qual for o tipo da violência que esteja sofrendo, devido à proximidade que esses profissionais têm com a comunidade a denúncia e notificação é facilitada.

Outro ponto discutido em todos os artigos é o fato do idoso não denunciar, dificultando ainda mais o rasteio. Um (01) estudo destacou um mecanismo de identificação de possíveis vítimas, argumentando que esses tipos de instrumentos têm contribuído na temática.

Formulação e reformulação de Políticas públicas foi assunto para três (03) dos estudos, discutiu-se quanto à eficácia das políticas e programas públicos, porém que ainda não existem prevenções eficazes contra a violência ao idoso, somente se trabalha com o cuidado curativo quando o preventivo seria o necessário.

O problema colocado pelos autores de dois (02) artigos foi o fato dos termos utilizados para definição dos tipos de violência e conceitos diferente de violência serem muitos, também dificultando a investigação dos casos.

Relacionados ao descritor "Idoso" e respondendo aos demais critérios de inclusão cinco (05) artigos foram analisados de ambas as bases de dados (Tabela 3).

Tabela 3

Artigos selecionados: com o descritor "idoso"

\begin{tabular}{|c|c|c|c|c|c|}
\hline $\begin{array}{l}\text { Bases de } \\
\text { Dados }\end{array}$ & $\begin{array}{c}\text { Artigos } \\
\text { encontrados }\end{array}$ & $\begin{array}{c}\text { Artigos em } \\
\text { L. Estrangeira }\end{array}$ & $\begin{array}{l}\text { Artigos } \\
\text { excluídos }\end{array}$ & $\begin{array}{c}\text { Artigos } \\
\text { selecionados }\end{array}$ & $\begin{array}{c}\text { Artigos } \\
\text { analisados }\end{array}$ \\
\hline SCIELO & 22 & $\begin{array}{c}0 \text { (Inglês) } \\
03 \text { (Português) } \\
0 \text { (Inglês/Português) }\end{array}$ & 07 & 15 & 03 \\
\hline PUBMED & 138 & $\begin{array}{c}01 \text { (Inglês) } \\
01 \text { (Português) } \\
40 \text { (Inglês/Português) }\end{array}$ & 135 & 02 & 02 \\
\hline & & & \multicolumn{2}{|c|}{ Total de Artigos Analisados } & 05 \\
\hline
\end{tabular}

Dois (02) artigos repetiram-se nas bases de dados: "Propriedades psicométricas daVulnerabilityto Abuse ScreeningScalerastreio de abuso contra idosos", e "PsychometricpropertiesoftheVulnerabilityto Abuse ScreeningScale forscreening abuse ofolderadults", sendo somado duplicadamente na tabela (2 e 3) porém referenciados no texto somente nos resultados e discussão da tabela 3.

O artigo além de explanar definições de violência, cita que são eventos que ocorrem quase que exclusivamente no ambiente familiar, mas, seu foco foi explanar sobre a 
importância de instrumentos/testes como o Hewalek-Sengstock (Teste de Rastreio do Abuso dos Idosos (H-S / EAST) e o Teste de Abuso do Cuidador (CASE), que coletam informações sobre possíveis abusos por parte dos cuidadores, porém destacam a Escala de Triagem de Vulnerabilidade ao Abuso (VASS) que apesar de ser considerada elegível no Brasil com o argumento de ser simples e autoadministravel, assim os autores concluíram que o instrumento mostrou-se um instrumento válido e com boa capacidade psicométrica para triagem de violência doméstica contra idosos no Brasil.

Os demais artigos (03) possuem uma padronização de envelhecimento da população a nível mundial, explanação sobre a violência contra o idoso e tipos de violência e sobre o ambiente familiar ser o de maior ocorrência da violência, sendo frisado por um (01) dos artigos que cuidar do idoso é responsabilidade da familia, mas, eles estão sendo agredidos por quem deveria zelar por eles. Devido ao conluio familiar o idoso, principal interessado, não se sente confortável em denuciar, ficando em comum acordo nos artigos que a denúncia seria a peça chave para um grande passo no contexto.

Somente dois (02) artigos responderam aos critérios de inclusão no que se refere ao descritor maus-tratos conforme apresentado na Tabela 4.

Tabela 4

Artigos selecionados com o descritor "maus-tratos"

\begin{tabular}{|c|c|c|c|c|c|}
\hline $\begin{array}{c}\text { Bases de } \\
\text { Dados }\end{array}$ & $\begin{array}{c}\text { Artigos } \\
\text { encontrados }\end{array}$ & $\begin{array}{c}\text { Artigos em } \\
\text { L. Estrangeira }\end{array}$ & $\begin{array}{l}\text { Artigos } \\
\text { excluídos }\end{array}$ & $\begin{array}{c}\text { Artigos } \\
\text { selecionados }\end{array}$ & $\begin{array}{c}\text { Artigos } \\
\text { analisados }\end{array}$ \\
\hline SCIELO & 22 & $\begin{array}{c}0 \text { (Inglês) } \\
02 \text { (Português) } \\
0 \text { (Inglês/Português) }\end{array}$ & 07 & 15 & 02 \\
\hline PUBMED & 138 & $\begin{array}{c}0 \text { (Inglês) } \\
0 \text { (Português) } \\
0 \text { (Inglês/Português) }\end{array}$ & 135 & 03 & 0 \\
\hline \multicolumn{5}{|c|}{ Total de Artigos Analisados } & 02 \\
\hline
\end{tabular}

Um dos artigos não difere dos demais quanto a explanação sobre o atual envelhecimento da população, mas, frisa que além de mudanças naturais do idoso os maus-tratos têm feito parte desse processo, também define os tipos mais comuns de maus-tratos e que as políticas e programas públicos que já possuímos no Brasil, apesar de ainda serem frágeis,são um grande avanço nesse contexto.

Fica claro que os autores se preocupam com a necessidade da responsabilização dos profissionais de saúde no que se refere a denúncia e notificação dos maus-tratos identificados e também a necessidade de conscientização da vítima sobre a denúncia, atribuindo o fato dos casos serem subnotificados a isso e aos diferentes tipos de termos que são utilizados para denominar os tipos de maus-tratos.

No mesmo artigo ainda se destaca que as diferentes formas de maus-tratos trazem consequências diversas para o idoso e que geralmente o agressor é um familiar da vítima, em geral um filho com algum tipo de problema financeiro o colocando na dependência da vítima ou até mesmo com problemas mentais e/ou dependente de álcool e drogas, assim sendo o idoso não quer formalizar a denúncia devido ao vínculo afetivo. 
O outro artigo define os maus-tratos e mantem seu discurso contextualizando a dificuldade de detecção devido pelo mesmo motivo identificado pelo artigo anterior: a vítima manter o agressor oculto por ser ele um membro próximo ou familiar. Mas frisa que há também o medo de sofrer represália por parte do agressor, culpa, vergonha e que não acreditem no seu relato.

É discutido ainda o profissional de saúde que não conhece sua função diante dos maus-tratos contra o idoso ou que como a vítima tem seus medos no momento de fazer a denúncia, por possivelmente não ter suporte para tal ato.

Tabela 5

Artigos organizados por base de dados, ordem cronológica, título e autoria.

Base de Dados: SCIELO

\begin{tabular}{|c|c|c|c|}
\hline & Ano & Título do artigo & Autores \\
\hline 1 & 2014 & $\begin{array}{l}\text { Capacidade funcional e situações de violência em } \\
\text { idosos. }\end{array}$ & FAUSTINO; GANDOLF; MOURA \\
\hline 2 & 2015 & $\begin{array}{l}\text { Agressões físicas e sexuais contra idosos notificadas } \\
\text { na cidade de São Paulo. }\end{array}$ & RODRIGUES; ARMOND; GORIOS \\
\hline 3 & 2015 & $\begin{array}{l}\text { Violência física e psicológica contra idosos: } \\
\text { prevalência e fatores associados. }\end{array}$ & PAIVA; TAVARES \\
\hline 4 & 2016 & $\begin{array}{l}\text { Violência intrafamiliar contra idosos: revisão } \\
\text { sistemática Intrafamilyviolenceagainsttheelderly: } \\
\text { systematic review. }\end{array}$ & CACHINA; PAIVA; TORRES \\
\hline 5 & 2016 & $\begin{array}{l}\text { Evidências psicométricas da adaptação transcultural } \\
\text { do Vulnerability Abuse ScreeningScale (VASS) para } \\
\text { detecção de violência contra idosos. }\end{array}$ & MAIA; MAIA \\
\hline 6 & 2016 & $\begin{array}{l}\text { Idosos vítimas de maus-tratos: cinco anos de análise } \\
\text { documental. }\end{array}$ & $\begin{array}{l}\text { GARBIN; JOAQUIM; } \\
\text { ROVIDA; GARBIN }\end{array}$ \\
\hline 7 & 2016 & $\begin{array}{l}\text { Maus-tratos contra idosos em Porto Alegre, Rio } \\
\text { Grande do Sul: um estudo documental. }\end{array}$ & $\begin{array}{c}\text { IRIGARAY; ESTEVES; } \\
\text { PACHECO; GRASSI-OLIVEIRA; } \\
\text { ARGIMON }\end{array}$ \\
\hline 8 & 2016 & $\begin{array}{l}\text { Prevalência de violência contra idosos e fatores } \\
\text { associados, estudo de base populacional em } \\
\text { Florianópolis }\end{array}$ & $\begin{array}{l}\text { BOLSONI; COELHO; GIEHL; } \\
\text { D'ORSI }\end{array}$ \\
\hline 9 & 2017 & $\begin{array}{l}\text { Maus-tratos no ambiente familiar contra idosos nas } \\
\text { Ilhas dos Açores. }\end{array}$ & $\begin{array}{c}\text { CARMONA-TORRES; } \\
\text { SILVA-CARVALHAL; } \\
\text { VIERA-MENDES; } \\
\text { RECIO-ANDRADE; } \\
\text { GOERGEN; } \\
\text { RODRÍGUEZ-BORREGO }\end{array}$ \\
\hline 10 & 2017 & $\begin{array}{l}\text { Prevalência de violência por parceiro íntimo em } \\
\text { idosos e fatores associados: revisão sistemática. }\end{array}$ & $\begin{array}{l}\text { WARMLING; } \\
\text { LINDNER; COELHO }\end{array}$ \\
\hline 11 & 2017 & $\begin{array}{l}\text { Propriedades psicométricas da Vulnerabilityto Abuse } \\
\text { ScreeningScalepara rastreio de abuso contra idosos. }\end{array}$ & DANTAS; OLIVEIRA; SILVEIRA \\
\hline
\end{tabular}




\begin{tabular}{|c|c|c|c|}
\hline & Ano & Título do artigo & Autores \\
\hline 12 & 2017 & $\begin{array}{l}\text { Violência contra idosos em três municípios } \\
\text { brasileiros. }\end{array}$ & $\begin{array}{l}\text { RODRIGUES; MONTEIRO; } \\
\text { SANTOS; PONTES; FHON; } \\
\text { BOLINA; SEREDYNSKYJ; } \\
\text { ALMEIDA; ACOMINI;DEFINA; } \\
\text { SILVA }\end{array}$ \\
\hline 13 & 2017 & $\begin{array}{l}\text { Violência contra os idosos brasileiros: uma análise } \\
\text { das internações hospitalares. }\end{array}$ & CASTRO; RISSARDO; CARREIRA \\
\hline 14 & 2018 & $\begin{array}{l}\text { Notification of intrafamily violence against elderly } \\
\text { women in the city of São Paulo }\end{array}$ & $\begin{array}{l}\text { GUIMARÃES; GÓRIOS; } \\
\text { RODRIGUES; ARMOND }\end{array}$ \\
\hline 15 & 2018 & $\begin{array}{l}\text { Prevalência e fatores associados à violência contra } \\
\text { idosos cometida por pessoas desconhecidas }\end{array}$ & ALENCAR JÚNIOR; MORAES \\
\hline \multicolumn{4}{|c|}{ Base de Dados: PUBMED } \\
\hline 16 & 2014 & $\begin{array}{l}\text { Políticas públicas para pessoas idosas no Brasil: uma } \\
\text { revisão integrativa. }\end{array}$ & $\begin{array}{l}\text { ANDRADE; SENA; } \\
\text { PINHEIRO; MEIRA; LIRA }\end{array}$ \\
\hline 18 & 2017 & $\begin{array}{l}\text { Psychometric properties of the Vulnerability to } \\
\text { Abuse Screening Scale for Screening abuse of older } \\
\text { adults. }\end{array}$ & DANTAS; OLIVEIRA; SILVEIRAI \\
\hline
\end{tabular}

\section{Conclusão}

No contexto geral dos artigos analisados por essa revisão sistemática de literatura, a temática da violência contra os idosos se mostra bem explanada e definida. Quando agregada as informações um artigo complementa o outro, ou seja, discute-se o envelhecimento da população, define-se a violência, os maus-tratos, os tipos de agressões, quem deve denunciar, as falhas no rastreio dos casos, a vítima principal interessada não denúncia por diversos motivos e que políticas e programas públicos são de fundamentais no norteamento do fenômeno.

Toda essa arguição é muito fundamentada e cientifica isso é obvio, mas, percebe-se que o que não foi discutido em nenhum dos artigos é como os serviços vão conseguir assistir toda a demanda existente de idosos sendo violentados no Brasil. A denúncia é colocada como um ponto chave para que se revolva o problema, contudo, a assistência específica para cada caso, será necessária.

\section{Referências}

Assis, F. S., \& Parra, C. R. (2014). Envelhecimento bem sucedido e a participação nos serviços de convivência para idosos. Psicologia, 1-8.

Barroso, A. J. B. (2016). O papel do Ministério Público em defesa da pessoa idosa. Recuperado em: 23 de julho de 2018 de <http://www.conteudojuridico.com.br/ artigo,o-papel-do-ministerio-publico- em-defesa-da-pessoa-idosa,56145.html > .

Boas, M. A. V. (2005). Estatuto do idoso comentado. Rio de Janeiro: Forense, pp. 216. 
Centro internacional de longevidade Brasil (ILC-BRASIL). (2015). Envelhecimento Ativo: Um marco político em resposta à revolução da longevidade. Rio de Janeiro: 2015. Instituto Brasileiro de Geografia e Estatística. (2017a) Censo 2010. Recuperado em: 23 de julho de 2018 de <https:/www.ibge.gov.br/estatisticas/sociais/populacao/9662censo-demografico-2010.html?edicao $=9673 \& \mathrm{t}=$ sobre $>$. IBGE.

Instituto Brasileiro de Geografia e Estatística. (2017b). Projeção da população do Brasil e das unidades da federação. Recuperado em: 23 de julho de 2018 de $<$ https://www. ibge.gov.br/apps/populacao/projecao/> . IBGE.

Lei n. 8.842, de 4 de Janeiro de 1994. (1994). Dispõe sobre a política nacional do idoso, cria o conselho nacional do idoso e dá outras providências. Brasília, 4 de janeiro, 1994. Recuperado em: 28 de julho de 2018 de <http://www.planalto.gov.br/ccivil_03/ leis/18842.htm>.

Lei n. 10.741, de $1^{\circ}$ de outubro de 2003. (2003). Dispõe sobre o Estatuto do Idoso e dá outras providencias. Recuperado em: 27 de julho de 2018 de $<$ http://www.planalto. gov.br/ccivil_03/leis/2003/110.741.htm>.

Lei n. 12.461, de 26 de Julho de 2011. (2011). Estabelece a notificação compulsória dos atos de violência praticados contra o idoso atendido em serviço de saúde. Brasília, 26 de junho, 2011. Recuperado em: 27 de julho de 2018 de $<$ http://www.planalto. gov.br/ccivil_03/_Ato2011-2014/2011/Lei/L12461.htm>.

Lei Orgânica do Ministério Público do Estado do Paraná. (1999). Lei Complementar Estadual n. 85, de 27 de Dezembro de 1999. Estabelece a Lei Orgânica e Estatuto do Ministério Público do Estado do Paraná. Curitiba, 27 de dezembro. Recuperado em: 27 de julho de 2018 de <http:/www.mppr.mp.br/arquivos/File/lomp7a.pdf>.

Lueger-Schuster, B., Gluck, T. M., Tran, U. S., \& Zeilinger, E. L. (2012). Sexual violence by occupational forces during and after World War II: influence of experiencing and witnessing of sexual violence on current mental health in a sample of elderly Austrians. InternationalPsychogeriatrics, 24(08), 1354-1358.

Mascarenhas, M. D. M., Andrade, S. C. A., Neves A.C.M., Pedrosa, A. A. G., Silva, M. M. A., \& Malta, D. C. (2012) Violência contra a pessoa idosa: análise das notificações realizadas no setor saúde - Brasil, 2010. Ciência e Saúde Coletiva, 9(17), 2331-2341.

Mazzilli, H. N. (1994). A Pessoa Idosa e o Ministério Público. Recuperado em: 21 de outubro de 2020 de: <http://www.mazzilli.com.br/pages/artigos/idoso.pdf >.

Mesquita, R. A. (2014). Envelhecimento e longevidade. Em: P. Papp (Org.) Tecnologia e Saúde: Debates Interdisciplinares. (pp. 123-156). Maringá: Unicesumar.

Pinto, F. N. F. R., Barham, E. J., \& Albuquerque, P. P. (2013). Idosos vítimas de violência: fatores sociodemográficos e subsídios para futuras intervenções. Estudos e Pesquisas em Psicologia, 3(13), 1159-1981.

Portaria n. 737 (2001, 16 de Maio). Política Nacional de Redução da Morbimortalidade por Acidentes e Violências. Recuperado em: 26 de agosto de 2018 de $<$ http://bvsms. saude.gov.br/bvs/saudelegis/gm/2001/prt0737_16_05_2001.html >.

Portaria n. 2.528 (2006a, 19 de Outubro). Política Nacional de Saúde da Pessoa Idosa. Recuperado em: 26 de agosto de 2018 de $<$ http://bvsms.saude.gov.br/bvs/saudelegis/ gm/2006/prt2528_19_10_2006.html>. 
Portaria n. 687 (2006b, 30 de Março). Aprova a Política Nacional de Promoção da Saúde. Recuperado em: 26 de agosto de $2018 \mathrm{de}<\mathrm{http}: / / 189.28 .128 .100 /$ dab/docs/legislacao/ portaria687_30_03_06.pdf $>$.

Portaria n. 528 (2013, 01 de Abril). Define regras para habilitação e funcionamento dos serviços de atenção integral às pessoas em situação de violência sexual no âmbito do sistema único de saúde. Recuperado em: 20 de junho de 2018 de $<$ http://bvsms. saude.gov.br/bvs/saudelegis/gm/2013/prt0528_01_04_2013.html>.

Portaria n. 1.271, (2014, 6 de Junho). Define a Lista Nacional de Notificação Compulsória de doenças, agravos e eventos de saúde pública nos serviços de saúde públicos e privados em todo o território nacional, nos termos do anexo, e dá outras providências. Recuperado em: 15 de junho de 2018 de < http://bvsms.saude.gov.br/bvs/saudelegis/ gm/2014/prt1271_06_06_2014.html>.

Programa das Nações Unidas para o Desenvolvimento (PNUD). (2014). Relatório do Desenvolvimento Humano 2014. Sustentar o Progresso Humano: Reduzir as Vulnerabilidades e Reforçar a Resiliência. Washington. Recuperado em: 12 de julho de 2018 de <dehttp://hdr.undp.org/sites/default/files/hdr2014_pt_web.pdf>.

Reichenheim, M. E., Paixão, C. M. Jr., \& Moraes, C. L. (2008). Adaptação transcultural para o português (Brasil) do instrumento Hwalek-Sengstock Elder Abuse Screening Test (H-S/EAST) utilizado para identificar risco de violência contra o idoso. Cadernos de Saúde Pública, 24(8), 801-1813.

Silva, M. R. F. (2016). Envelhecimento e proteção social: aproximações entre Brasil, América Latina e Portugal. Serviço Social \& Sociedade, 126, 215-234.

Sampaio, R. F., \& Mancine, M.C. (2007). Estudos de revisão sistemática: um guia para síntese criteriosa da evidência científica. Revista Brasileira de Fisioterapia, 1(11), 83-89.

World Health Organization (2014). Global Status Report on Violence Prevention 2014. Geneva: World Health Organization. (WHO). Recuperado em: 26 de julho de 2018 de $<$ https://www.who.int/violence_injury_prevention/violence/status_report/2014/ en $/>$.

Cassiana Regina Leindecker: Discente do Curso de Mestrado em Promoção da Saúde, Centro Universitário de Maringá - UNICESUMAR. Bolsista PIBIC/CNPq-UniCesumar. - Endereço: Rua 8 de Setembro, 446 Casa A Cep.: 87014-380, Bairro: Jardim Alamar, Maringá UF: Paraná, Fones: (44) 9869-0999.

Rose Mari Bennemann: Co-orientadora - Docente no Mestrado em Promoção da Saúde, Centro Universitário de Maringá - UNICESUMAR. Pesquisadora do Instituto Cesumar de Ciência, Tecnologia e Inovação - ICETI - Endereço: Avenida Guedner, 1610 Cep.: 87050-900, Bairro: Jardim Aclimação, Maringá UF:Paraná, Fones: (44) 3027-6360.

Regiane da Silva Macuch: Orientadora - Docente no Mestrado em Promoção da Saúde, Centro Universitário de Maringá - UNICESUMAR. Pesquisadora do Instituto Cesumar de Ciência, Tecnologia e Inovação - ICETI - Endereço: Avenida Guedner, 1610 Cep.: 87050-900, Bairro: Jardim Aclimação, Maringá UF:Paraná, Fones: (44) 3027-6360.

E-mail para contato: cassianarl@gmail.com. 